\title{
Using Artificial Intelligence in Learning English as a Foreign Language: an Examination of IELTS LIULISHUO as an Online Platform
}

\author{
Ruolin Li \\ School of foreign languages, Northeast Normal University, Changchun 130024, Jilin, China \\ E-mail: irisli0706@163.com
}

\begin{abstract}
EFL (English as a foreign language) learners seem destined to make errors and continuously need to test their changing language levels. However, the unbalance between supply and demand always exists in the process of learning English. Teachers sometimes are also tired of doing repetitive jobs to correct the same mistakes of nonnative speakers. Therefore, many researchers tend to improve the efficiency of learning and teaching processes by using computer-assisted instruction. Specifically, artificial intelligence software is an unstoppable trend to solve this problem. This study aims to find which characteristics in IELTS Liulishuo (an artificial English-learning app to improve IELTS performance) are following the elements of computer-assisted language learning (CALL) pedagogy (Chapelle, 2003). ${ }^{[1]}$ Meanwhile, it will also be evaluated under the mobile-assisted language learning (MALL) principles and some concepts of AI-powered foreign language software, as was put forward by Stockwell (2013) and Pokrivcakova (2019). The results showed that IELTS Liulishuo has affordability to be used as an online platform for foreign English learning. More importantly, it shed some light on CALL pedagogy and the design of artificial applications of foreign language learning. ${ }^{[2-3]}$

Keywords: computer-assisted language learning, mobile-assisted language learning, learning English as a foreign language, artificial intelligence, IELTS
\end{abstract}

\section{Introduction}

\subsection{Computer-assisted language learning and mobile-assisted language learning}

The computer was probably regarded as a satisfying and innovative method to learn languages. As was suggested by Levy (1997), CALL is "the search for and study of applications of the computer in language teaching and learning". At the same time, Levy (1997) and Chapelle (2001) discovered the feature of CALL, which contains a lot of other disciplines. One of the prominent theories of computer-assisted language learning pedagogy contains L2-input exposure, interaction and linguistic production (Chapelle, 2003). ${ }^{[4-5][1]}$

Through the rise of mobile devices, more and more people focus on learning on a small screen. Kukulska-Hulme (2013) defined that MALL is the use of "mobile technologies in language learning, especially in situations where device portability offers specific advantages". ${ }^{[6]}$ Among numerous studies of MALL, it is possible to summarize some principles and apply them into learning on mobile devices. Elias (2011) put forward eight principles, and four of them are more targeted to language learning. ${ }^{[7]}$ See Figure 1.

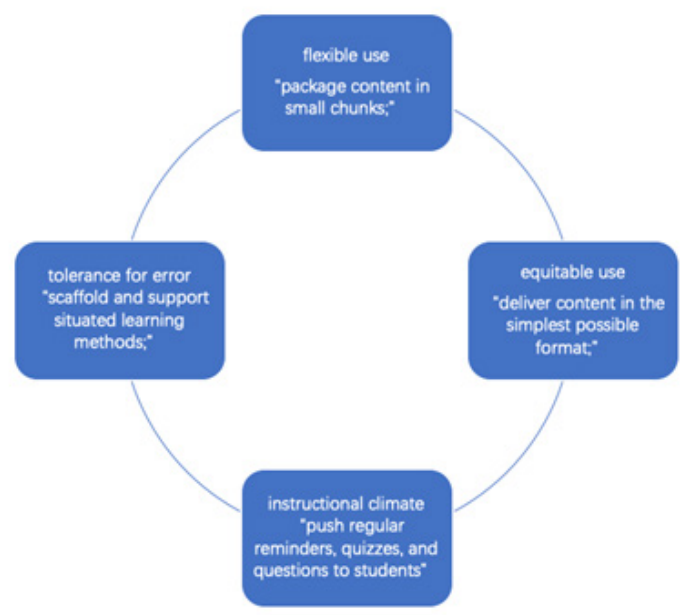

Figure 1. Four principles of MALL 
Due to the reason that MALL owns a large amount of the same content with CALL, it is best to combine themselves instead of setting them apart. (Stockwell, 2013). Therefore, this paper aims to examine whether the IELTS Liulishuo conforms to those principles of CALL and MALL. ${ }^{[2]}$

\subsection{Artificial intelligence in foreign language learning}

AI-assisted devices in foreign language learning is a sub-class of computer-assisted language learning (CALL). With the rapid growths of natural language processing and technology to deal with big data, AI has a large number of improvements in foreign language education. The shift from CALL to ICALL (Intelligent CALL) has been unstoppable and brought a significant change in the quality of student-computer interaction (Kannan \& Munday, 2018). ${ }^{[8]}$ Pokrivcakova (2019) summarizes that there are seven categories in applying artificial intelligence into foreign language learning. Applying AI-assisted language learning platforms is one of crucial category among them. ${ }^{[3]}$

Within this class, it also can be divided into two classifications: the conventional graphical user interface with speech recognition and language interface with dialogue function (Lotze, 2018). ${ }^{[9]}$

There is a considerable amount of applications and platforms which still use the conventional graphical user interface. The main reason lies in the fact that they are not that difficult to build. They make learners stick on different practices and make them in small chunks such as filling gaps, drilling, matching exercises. The drawback of this way is that they lack enough creativity and individualized content. Meanwhile, those platforms cannot give feedbacks in detail in terms of grammar, pronunciation and other categories. Stockwell (2013) has analyzed some relations among CALL, MALL and ML (mobile learning). However, none of the researchers summarizes the relations among CALL, ICALL (also can be understood as AI-assisted language learning) and MALL. They are independent concepts but also rely on each other inalienably. ${ }^{[2]}$ See Figure 2.

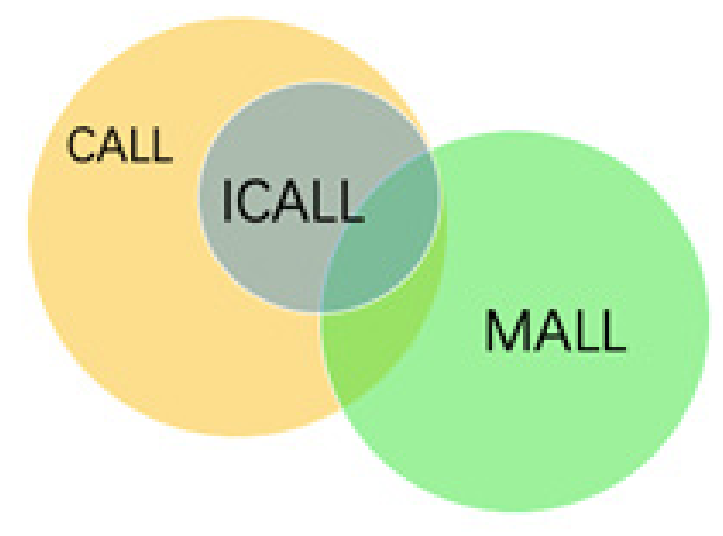

Figure 2. The relationship among CALL, ICALL and MALL

\section{An overview of IELTS Liulishuo}

English Liulishuo App is one of the mainstream AI-assisted applications in China. The research shows an upward result that this platform can improve the efficacy of students' oral English. ( Liu, Yang \& Xu, 2019). ${ }^{[10]}$

IELTS Liulishuo is another AI-powered application created by Shanghai Liulishuo Information Technology Ltd. Although it is a kind of a platform under the category of the conventional graphical user interface, it still cuts new edge in targeting highly exam-oriented learning materials.

It aims to improve two productive skills, including speaking and writing, combined with instant feedback on IELTS band in some close tasks. At the same time, learners can also test themselves by entering the mock exam.

\subsection{The mock IELTS speaking test}

In IELTS Liulishuo, users can enter into a simulation test with an interactive video of a real examiner. After the test, learners can get a thorough report in terms of four band descriptors involving grammar, fluency, vocabulary and pronunciation. See Figure 3. 


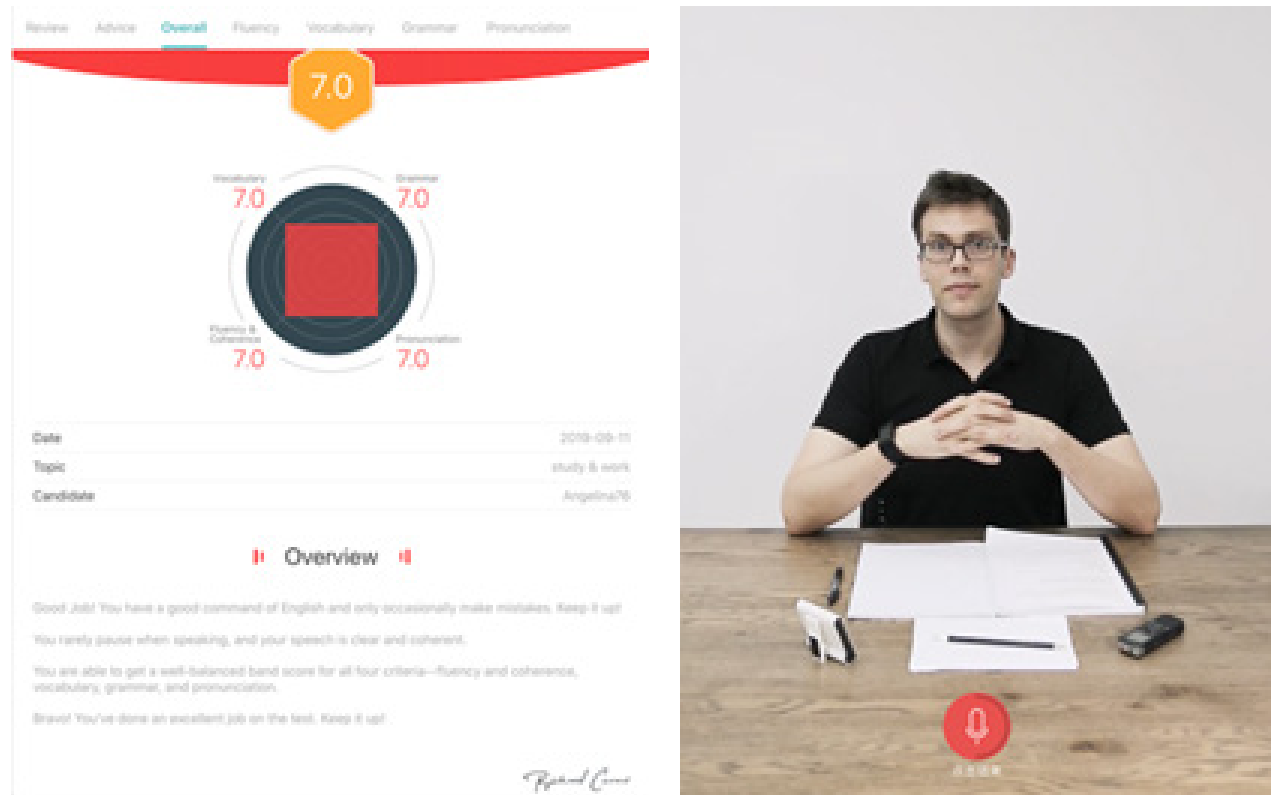

Figure 3. The screen of mock IELTS test of IELTS Liulishuo

\subsection{The close module courses of speaking and writing}

According to different scoring criteria and different topics in the IELTS test. The designers of the application create many close curriculums integrated with speech recognition. There are many types of exercises, such as gap filling, drilling, matching activities, translation. Furthermore, every module has pre-test and pro-test with scoring and feedbacks to enable learners to visualize the advancement instantly. See Figure 4.

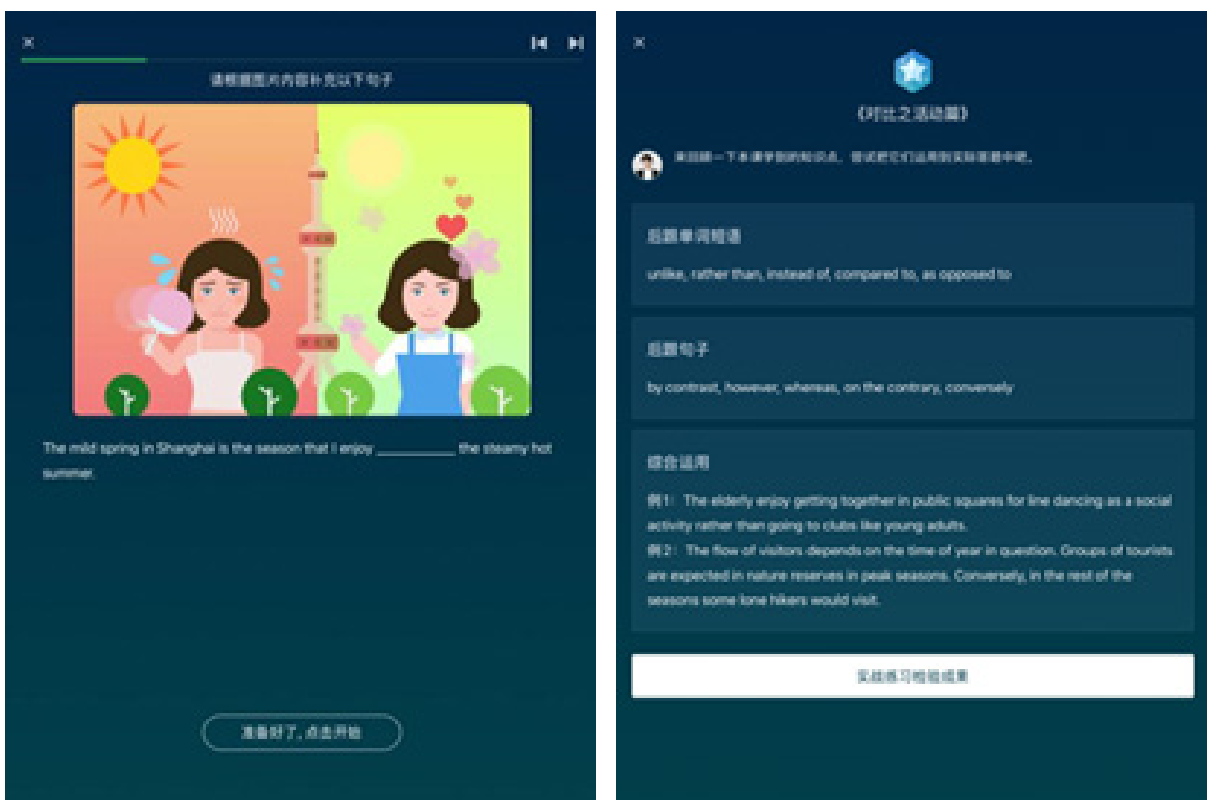

Figure 4. The screen of close tasks of IELTS Liulishuo

\section{Evaluation}

The author aims to examine the IELTS Liulishuo's characteristics under the principles of CALL, MALL and AI. Specifically, the study will concentrate on CALL pedagogy put forward by Chapelle (2003) ${ }^{[1]}$ : L2-input exposure, interaction and linguistic production and the four MALL principles suggested by Elias (2011) ${ }^{[7]}$, including equitable use, flexible use, tolerance for error, and instructional climate. Additionally, this application will also be evaluated among some frameworks in AI-powered foreign language learning. 


\subsection{CALL pedagogy elements in IELTS Liulishuo}

IELTS Liulishuo contains necessary frameworks of CALL pedagogy suggested by Chapelle (2003), namely, L2-input exposure, interaction and linguistic production. In the section of pre-designed courses of speaking and writing, learners can immerse in L2-input and also in the mock test part. When it comes to interaction, the features of the application lie more in the feedback. Afterwards, learners output their utterances, answering different topic questions as linguistic production. ${ }^{[1]}$

\subsection{MALL principles in IELTS Liulishuo}

As for equitable use in the software, many tasks are genuinely designed for the smallest format to practice such as matching activities, gap filling and drilling. Similarly, as an innovative platform, IELTS Liulishuo also packs different knowledge point in terms of standards of scoring in chunks, which meets the criteria of flexible use. For tolerance for error, it does give issue warnings using text. However, when it comes to some corrections or feedbacks given by the software, sometimes it fails to deliver accurate information without access to posts efficiently. Nevertheless, it does create an instructional climate by giving quizzes and questions to students.

\subsection{Under the comparisons and frameworks in EFL AI-powered software}

Suppose we take a glimpse at the frameworks of different AI-powered software. In that case, we can discover that IELTS Liulishuo more likely belongs to the conventional graphical user interface with speech recognition and language interface (Lotze, 2018). ${ }^{[9]}$ The problem is that the platform cannot support real individualized courses according to different levels and paces of learners. All curriculums are pre-designed and will send to the user interface randomly. Furthermore, it cannot communicate with learners using dialogue instantly, which is known as the functions of some chatbots.

\section{Conclusion and recommendation}

In conclusion, IELTS Liulishuo fits the CALL pedagogy and some principles of MALL and AI-powered software, which endows affordability for EFL learning. The most outstanding value of this application lies in combining the AI technology with exam orientation, to be more specific, IELTS test. However, there are still some shortages such as tolerance of errors, innovative space, individualized content and highly collaborative learning processes. Significantly, sometimes it will have false corrections toward learners' speaking, which are not allowed learners to send immediate and efficient feedbacks to improve the feedback. The author also noticed that every report of the mock IELTS test is in English using some specialized words such as "infinitive". It is not user-friendly enough for nonnative speakers, especially for those beginners, which lead to the demand of two versions of feedbacks for testers including L1 and L2.

Although the improvement of AI-assisted EFL apps has been boosted, we still need to continuously examine the affordability of those mobile applications through the change of time, examining different concepts and investigating the perceptions of both instructors and learners.

\section{References}

[1] Chapelle C. (2003). English Language Learning and Technology: Lectures on Applied Linguistics in the Age of Information and Communication Technology (Vol. 7). Amsterdam, Philadelphia: John Benjamins Publishing.

[2] Stockwell G, Hubbard P. Some Emerging Principles for Mobile-assisted Language Learning. The International Research Foundation for English Language Education. 2013; (2013): 1-15. Available from: https://doi.org/10.5539/ijel. v3n1p19.

[3] Pokrivcakova S. Preparing teachers for the application of AI-powered technologies in foreign language education. Journal of Language and Cultural Education. 2019; 7(3): 135-153. Available from: https://doi.org/10.2478/ jolace-2019-0025.

[4] Levy M. (1997). Computer-assisted language learning: Context and conceptualization. Oxford University Press.

[5] Chapelle C. (2001). Computer applications in second language acquisition: Foundations for teaching, testing and research. Cambridge, United Kingdom: Cambridge University Press.

[6] Kukulska-Hulme A. (2013). Mobile-assisted language learning. In: C. Chapelle (Ed.). The encyclopedia of applied linguistics (pp. 3701-3709). New York: Wiley.

[7] Elias T. Universal instructional design principles for mobile learning. International Review of Research in Open and Distance Learning. 2011; 12(2): 143-156. Available from: http://www.eric.ed.gov/PDFS/EJ920738.pdf.

[8] Kannan J, Munday P. New trends in second language learning and teaching through the lens of ICT, networked 
learning, and artificial intelligence. In: Fernández Juncal, C. \& Hernández Muñoz, N. (Eds.), Vías de transformación en la enseñanza de lenguas con mediación tecnológica. Círculo de Lingüística Aplicada a la Comunicación. 2018; 76: 13-30. Available from: http://dx.doi.org/10.5209/CLAC.62495.

[9] Lotze N. (2018). Goodbye to classroom teaching? Artificial intelligence in language learning. Translation: Chris Cave. Copyright: Goethe-Institut e. V., Redaktion Magazin Sprache. Available from: https:/www.goethe.de/en/spr/mag/ dsk/21290629.html?forceDesktop=1.

[10] Yang L, Tong Y, Siyuan X. The Efficacy of Using Liulishuo for Spoken English Ability — Taking the Practice of Liulishuo in North China Electric Power University (Baoding) as an Example. International Education Studies. 2019; 12(4): 244. Available from: https://doi.org/10.5539/ies.v12n4p244. 